Dr. Rodolfo Oroz S.

\title{
La enseñanza de la filosofía en nuestros días
}

$S$ un hecho incontestable que entre los problemas filosóficos que menos les agradan a nuestros alumnos, porque les presentan muchas dificultades, figuran con otros tantos, los de la lógica formal. ¿Por qué será así? ¿Es el profesor el culpable o el alumno? A mí me parece que esta parte de la filosolia es una materia que no corresponde a la mentalidad de los alumnos del quinto año de humanidades. Sin embargo, en el programa de filosolía correspondiente al quinto año de humanidades, la lógica formal ocupa una parte muy extensa: los silogismos, figuras y modos del silogismo (l). etc., etc. En el sexto año vemos, entre otros muchos problemas, que prescribe programa, el análisis mental, la clasificación de las ciencias, de Comte y de Wundt, y su crítica. Métodos en las Matemáticas, física, ciencias biológicas, sistemas o teorías sobre la filosofía de la historia, etc., etc.

¿Por qué maltratar los espíritus jóvenes y sensibles con estos problemas estériles? ¿Estamos realmente convencidos de que con estos medios los alumnos van a descubrir la verdad o sus características? No seamos tan exigentes como el siglo XVII.

La preparación filosófica en los liceos, no cabe duda, es conveniente, - aunque no absolutamente necesaria.-Conveniente, digo, porque contribuye a desarrollar y afirmar la capacidad necesaria para tratar y comprender problemas lógicos y especulativos asi como para llegar a un concepto general de las distintas ramas de la ciencia. A este fin debieran concurrir, fuera del castellano, los demás ramos cientificos, con debida correlación en este punto.

Pero en la enseñanza secundaria hay que moderarse en esta materia, si no, se perdería fácilmente la orientación y el peligro es grande, ateniéndose estrictamente al programa actual.

La preparación filosófica que proporciona la Universidad es ciencia teórica, especulativa; se ocupa del conocimiento y pensamiento; pero el estudio filosófico en la escuela debe moverse en otra dirección, pues debe tratar de dar a los alumnos una cultura en el sentido común de la palabra, darles los valores que fortalecen su 
alma, que facilitan su desarrollo interior. No debe contentarse con lo puramente formal, hay que imponerle un contenido, echarle una gota de idealismo.

El estudio (1) de la filosofía en la Universidad es esencialmente intelectualista: en la escuela, esencialmente universalista; es decir, se dirige al hombre en su totalidad como un ser que siente, que quiere, aprecia y piensa.

¿Qué es lo que significa pensar filosóficamente? Empezamos a pensar filosóficamente cuando clasificamos a los fenómenos o hechos particulares bajo un punto de vista más general, universal, cuando relacionamos lo transitorio con lo permanente. analizamos las cosas o buscamos las causas de los fenómenos. Se puede dar a la enseñanza un carácter filosófico en todos los cursos superiores del liceo: buscando la unidad en la variedad, comparando lo relacionado con lo parecido, reuniendo lo separado, buscando relaciones interiores entre lo que, al parecer, es desigual; buscando leyes donde el observador superficial no vé sino una serie de fenómenos aislados e independientes los unos de los otros, reconociendo una necesidad donde otros por su observación inexacta y superficial, sólo ven algo accidental, recibiendo. así, impulsos para pensar e investigar nuevamense aún lo que a la experiencia diaria parece cierto y acabado. El objeto de la enseñanza filosófica en la escuela no consiste en tratar la historia de la filosofía, como lo prescribe el programa actual. ni transmitir un sistema determinado. sino en producir en los alumnos una disposición filosófica, crear un modo de pensar filosóficamente que se mantiene firme en el torbellino de las opiniones que hay sobre lo humano y lo divino. y que facilita el discernimiento de objeciones fundadas de argumentos falsos o aparentes, sofismas.

Mi estimado profesor Eduardo Stranger, ahora profesor de filosofía y pedagogia en la Universidad de Berlin. decia, refiriéndose a la enseñanza secundaria: renseñemos filosóficamente, pero no enseñemos filosofia. No se trata, evidentemente, aquí del modo de hacer clases que brillan por algunas observaciones ingeniosas oportunamente intercaladas. sino que la altura espiritual de la enseñanza que quiere educar para el trabajo de pensar debe manifestarse sobre todo: $10^{\circ}$ en la seguridad de establecer los problemas; $2 .^{\circ}$ en la difinición absolutamente exacta de los conceptos; $3 .^{\circ}$ en la habilidad de despertar el interés por todo lo que ofrezcan la ciencia, el arte y la vida como medios para obtener conocimientos nuevos y más amplios. Pero, a estos puntos de importancia fundamental para cualquier trabajo científico, se ha prestado hasta ahora muy poca o ninguma atención. Esto me lo prueban cada año los alumnos que ingresan al Pedagógico. No me parece, sin embargo. demasiado dificil remediar este defecto con tal que se elija como principio la limitación. La preparación filosófica exige en todo limitación y prudencia.

(1) Advierto que no se puede sestudiars filosofia en el sentido como se esfudia, por ejemplo. filosofia clásica o moderna o química. Esto no conviene ni siquiera para la historia de la filosolia. aunque ésta, propiamente, no es filosolia, sino historia no más porque estos esfudios de carácter histórico deben esfar en intima relación con los problemas filosóficos, si quieren alcanzar alguna importancio. 
Al tratar y estudiar lógica, psicológica e históricamente la lengua madre, el prolesor de castellano puede darles a los alumnos, sin que éstos se den cuenta. una introducción a las leyes lógicas y de evolución de nuestro espíritu; luego. exponer el principio de lo que es concepto, juicio y conclusión; a propósito de la explicación psilógico ética de dramas, el profesor aprovechará la ocasión de referirse a los elementos de nuestra vida interior, con todas sus disposiciones e inclinaciones, motivos y pasiones; luego pasará al dominio de la razón que forma las ideas y al de la fantasía creadora, para tocar los problemas de la libertad moral y la responsabilidad, el destino y el carácter. Pues filosofía es la ciencia del pensar, del uso correcto de la razón, de la formación de conceptos e ideas; pero también de los valores de la vida. Sale de lo particular y conduce a lo universal, para volver después a lo particular. Pero, en todas las ciencias, asi como sistemas filosóficos, la idea, o, mejor dicho, el convencimiento fundamental, ha sido siem ${ }^{-}$ pre la fuerza impulsora. Tal fuerza debe ser la resultante de la enseñanza que se empeña por el desarrollo del amor a la verdad, con referencia a la ética y a la ciencia. ¿Cuál será la luerza del alma en que arraiga ese amor a la verdad? ¿No será ésa, como lo dije yá en otra ocasión, El fin Universal, al respecto? La admiración que nos causa respeto produce en nosotros, al mismo tiempo, el deseo de buscar su motivo y nos lleva asi al conocimiento.

El que reconoce el límite de lo empírico y con esto llega como Sócrates al convencimiento de no saber nada. y el que no honra el mundo y la vida como un hecho natural, sino como un problema, puede llamarse filósofo.

En las clases de literatura española hay mucha ocasión para discutir sobre los problemas que surgen a cada instante: ¿Cuál es el sentido de nuestra vida? ¿Qué significa el movimiento permanente en el destino de los pueblos? ¿Qué importancia tiene el individuo? ¿Qué tengo que hacer para servir a la humanidad y para que yo sea feliz? ¿Qué es lo que exige, ofrece y promete la vida en el presente y en el futuro? Sentimos todos que hay un secreto detrás de las apariencias, detrás de la corteza de las cosas. Pero es precisamente este conocimiento que nos hace aparecer maravilloso lo más pequeño y lo más grande en este mundo. Eso es lo que causa sumisión. humildad y respeto en nosotros.

La preparación filosófica en la escuela, pues, debe ser esencialmente filosolía práctica, filosofía de la vida, quiero decir, dando nociones de la vida, según sus múltiples formas; debe ser un guía que nos dé la dirección para poder servir a la patria y a la humanidad en general: filosofía en forma de un idealismo ético sobre la base nacional.

DR. RODOLFO OROZ S. 